\title{
Unusual airway situation: esophageal stethoscope knotted around endotracheal tube
}

\author{
Sergey V. Pisklakov ${ }^{1 *}$ and Orion S. Hine ${ }^{2}$ \\ *Correspondence: pisklase@umdnj.edu \\ 'Department of Anesthesiology and Perioperative Medicine, University of Medicine and Dentistry of New Jersey, New Jersey Medical \\ School, USA. \\ ${ }^{2}$ Department of Anesthesiology and Perioperative Medicine, University of Medicine and Dentistry of New Jersey, New Jersey Medical \\ School, USA.
}

\begin{abstract}
The following is an account of a rare airway management situation not previously described in the literature: an esophageal stethoscope knotted around the endotracheal portion of an endotracheal tube with difficulty removing either device independently. While many articles have reported an endotracheal tube entangled with an orogastric or nasogastric tube, this is the first such description of an esophageal stethoscope encountering the same problem. The patient involved in this case report was a 68 year old Hispanic female with a history of supratentorial meningioma, status post resection 6 months prior, now requiring ventriculoperitoneal shunt placement. Anesthetic induction and intraoperative course were uneventful, with the difficulty at extubation being the focus of this case report. Although this case is the first of its kind to be described; the conclusions drawn from it are widely applicable. Namely, that if any device near or in the airway becomes difficult to remove it should be left in place until extubation and then simultaneously removed with the endotracheal tube.
\end{abstract}

Keywords: Airway management, retained endotracheal tube, perioperative airway complications, esophageal stethoscope knotting

\section{Introduction}

Many anesthesiologists routinely monitor temperature and respiratory function with an esophageal stethoscope. The device consists of a soft plastic catheter, sized 8 to 24 French, with balloon-covered distal openings. Originally used solely to auscultate heart and breath sounds, esophageal stethoscopes now can have temperature probes, atrial pacemaker probes, ECG leads, or ultrasound probes built into them. Esophageal stethoscopes are passed down into the esophagus via the mouth or nose. Placement of these devices very rarely cause complications. However, mucosal irritation and bleeding are the most commonly noted complications of esophageal stethoscope use, while endotracheal placement creating a gas leak around the tracheal tube cuff is perhaps the most serious [1-3]. Direct contraindications to the placement of these instruments include esophageal surgery and esophageal varices or strictures.

\section{Case}

We had a 68 year old female with history of supratentorial meningioma, status post resection, now requiring ventriculoperitoneal shunt placement. Preoperative labs were all within normal limits and physical examination was unremarkable with the airway noted to be Mallampati class two with normal cervical range of motion, mouth opening and thyromental distance. A smooth intravenous induction was performed and the patient was easily intubated with a 7.0 ETT on the first attempt. To monitor temperature an esophageal stethoscope with temperature probe was easily placed via the mouth with no resistance noted. Intraoperatively, the patient's vital signs remained stable and the operation was performed in approximately one and one half hours without complications. During this time temperature data from the esophageal stethoscope remained constant and within normal limits.

At the end of the case the decision to extubate the patient was made as all criteria were met. Esophageal stethoscope removal was attempted prior to extubation, but great resistance to removal was felt. In addition, every attempt to remove the esophageal stethoscope caused a similar movement of the endotracheal tube (ETT). Being unable to remove the esophageal stethoscope or the ETT separately, the decision was made to remove both simultaneously. This maneuver was successful. The patient was extubated, removing what is shown in Figure 1. Apparently, the esophageal stethoscope looped around the ETT on insertion and formed a knot. Upon removal, the tension applied caused the knot to be drawn further down the esophageal stethoscope and tighten around the ETT. Postoperatively the patient suffered no trauma and had no complaints of sore throat from the misplaced esophageal stethoscope or its removal.

\section{Discussion and Conclusion}

The above described complication is noted to be unique. We did not find a single case of esophageal stethoscope 


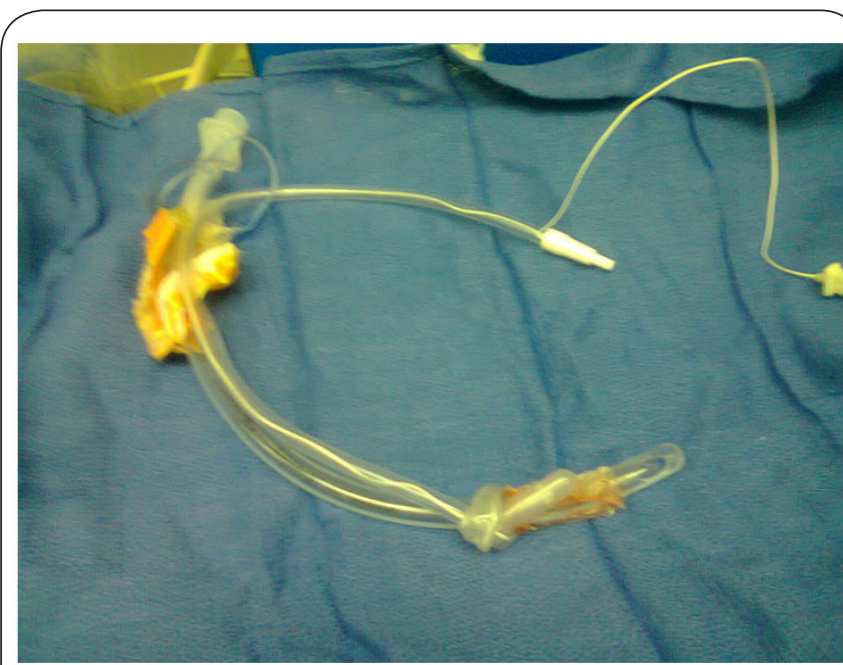

Figure 1. Stethoscope knotted tightly around the ETT.
Competing interests

The authors declare that they have no competing interests.

\section{Authors' contributions}

This work was carried out in full collaboration between both authors. Sergey Pisklakov and Orion Hine equally participated in drafting and revising of this manuscript. Both authors equally managed the analysis of the case, the literature searches, read and approved the final manuscript.

\section{Acknowledgement}

Sergey Pisklakov and Orion Hine would like to acknowledge Professor Rex Ponnudurai, MD for his guidance and mentorship.

Publication history

Received: 29-May-2013 Revised: 04-Jun-2013

Accepted: 08-Jun-2013 Published: 13-Jun-2013

\section{References}

1. Schwartz AJ and Downes JJ: Hazards of a simple monitoring device, the esophageal stethoscope. Anesthesiology 1977, 47:64-5. | Article | PubMed

2. Ritter DM, Rettke SR, Hughes RW Jr, Burritt MF, Sterioff S and Ilstrup DM: Placement of nasogastric tubes and esophageal stethoscopes in patients with documented esophageal varices. Anesth Analg 1988, 67:283-5. | Article | PubMed

knotting around ETT described in the literature. Similar cases involving orogastric or nasogastric tube entanglement or obstruction of ETTs were noted [4-11]. All reports share a common characteristic with each other: difficulty placing the gastric tube. In our case we had no resistance to esophageal stethoscope placement. Just like when gastric tubes passed blind esophageal stethoscope has the potential for knotting or misplacement into trachea. Possible signs of an esophageal stethoscope being entangled with an ETT include difficulty of removing the stethoscope independently of the ETT, gas leak upon ventilation via the ETT, and patient temperature that fluctuates with ventilation (provided the stethoscope contains a temperature probe). Our finding indicates that if great resistance to removal of esophageal stethoscope is encountered it is best managed by simultaneous removal of both the esophageal stethoscope and the ETT. This is a case of uneventful VP shunt placement surgery with inability to remove esophageal stethoscope or ETT independently at end of the case. The decision to remove both simultaneously was made and upon doing so the esophageal stethoscope was noted to be knotted tightly around the ETT.

Any difficult insertion or removal of an esophageal stethoscope should prompt immediate investigation to rule out possible knotting of the esophageal stethoscope around the ETT. If any resistance is felt upon removal of esophageal stethoscope anesthesiologist should have a high index of suspicion for knotting to the ETT. When any doubts exist chest radiography should be sought to evaluate esophageal stethoscope placement in a same manner as it is done evaluating gastric tube placement [12-14]. Similar to retained orogastric tube, continued attempt at extraction of a retained esophageal stethoscope may cause unintentional extubation, respiratory compromise, tracheolaryngeal and oropharyngeal trauma [11].
3. Domino KB, Posner KL, Caplan RA and Cheney FW: Airway injury during anesthesia: a closed claims analysis. Anesthesiology 1999, 91:1703-11. | Article I PubMed

4. Raikhelkar J and Denman WT: A knotty problem. J Clin Anesth 2003, 15:571-2. | Article | PubMed

5. Asai T, Hidaka I and Kawachi S: Inadvertent insertion of a gastric tube into the airway in an awake patient. Can J Anaesth 2002, 49:322. | Article | PubMed

6. Agarwal A, Gaur A, Sahu D, Singh PK and Pandey CK: Nasogastric tube knotting over the epiglottis: a cause of respiratory distress. Anesth Analg 2002, 94:1659-60. | Article | PubMed

7. Au-Truong X, Lopez G, Joseph NJ and Salem MR: A case of a nasogastric tube knotting around a tracheal tube: detection and management. Anesth Analg 1999, 89:1583-4. | Article | PubMed

8. Pousman RM and Koch SM: Endotracheal tube obstruction after orogastric tube placement. Anesthesiology 1997, 87:1247-8. | Article | PubMed

9. Bautista EM: Complications of nasogastric tube insertion. Chest 1988, 93:1119-20. | Article | PubMed

10. Melki I, Matar N, Maalouf S and Rassi S: Knotting of nasogastric tube around a nasotracheal tube: An unusual cause of hypercapnia in a 3-month-old infant. Am J Crit Care 2010, 19:198-7. | Article | PubMed

11. Young MJ and Ehrenfeld JM: Knotting of an orogastric tube around an endotracheal tube. J Clin Anesth 2012, 24:254-5. | Article | PubMed

12. Baskin WN: Acute complications associated with bedside placement of feeding tubes. Nutr Clin Pract 2006, 21:40-55. | Article | PubMed

13. Sorokin R and Gottlieb JE: Enhancing patient safety during feedingtube insertion: a review of more than 2,000 insertions. JPEN J Parenter Enteral Nutr 2006, 30:440-5. | Article | PubMed

14. Richardson DS, Branowicki PA, Zeidman-Rogers L, Mahoney J and MacPhee M: An evidence-based approach to nasogastric tube management: special considerations. J Pediatr Nurs 2006, 21:388-93. I Article | PubMed

\section{Citation:}

Pisklakov SV and Hine OS: Unusual airway situation: esophageal stethoscope knotted around endotracheal tube. journal of Anesthesiology and Clinical Science 2013, 2:24. http://dx.doi.org/10.7243/2049-9752-2-24 